\title{
Las fuerzas armadas en tiempos de paz
}

\section{The Armed Forces during peace times}

\author{
Edwin Cruz Rodríguez
}

Politólogo, candidato a doctor en Estudios políticos e integrante del Grupo de Investigación en Teoría Política Contemporánea de la Universidad Nacional de Colombia.

Cómo citar: Cruz, E. (2016). Las fuerzas armadas en tiempos de paz. Inciso, 18 (2):69-86.

Recibido: 06/01/2016| Revisado: 18/02/2016| Aceptado: 25/0916

\section{Resumen}

Este trabajo examina el rol de las Fuerzas Armadas en las negociaciones de paz en una perspectiva histórica, para comprender la situación actual. La persistencia del conflicto armado ha imposibilitado la ruptura con el esquema de relaciones cívico-militares que estableció el Frente Nacional y que asegura la subordinación de los militares al poder civil a cambio de una autonomía relativa para el manejo de los asuntos de su campo. Las tensiones entre civiles y militares que este esquema produce se recrudecen en coyunturas de negociación con la insurgencia porque se producen oportunidades políticas para intentar mantener o ampliar la autonomía. Aunque el gobierno Santos ha articulado las Fuerzas Armadas al proceso de paz no ha conseguido transformar dicho esquema.

Palabras clave: Colombia, Fuerzas Armadas, negociaciones de paz, relaciones cívico-militares

\begin{abstract}
This work examines the Armed Forces role in peace negotiations within a historical perspective, in order to understand current situation. Armed conflict persistence has prevented a rupture with the civil-military relations scheme established by the National Front, which ensures military subordination to the civil power, in exchange for a relative autonomy to manage those issues of its field. Civil military tension produced by such scheme increases during negotiation with the insurgence, because of production of political opportunities to keep or expand autonomy. Although Juan Manuel Santos Administration has involved the Armed Forces in the peace process, he has not managed to transform such scheme.
\end{abstract}

Keywords: Colombia, Armed Forces, Peace negotiations, civil-military relations. 


\section{Introducción}

Uno de los actores fundamentales en los procesos de construcción de paz en contextos de conflicto armado interno son las Fuerzas Armadas (FF.AA.), puesto que sus posiciones tienen una alta incidencia en el curso de las negociaciones (Schultze-Kraft, 2005). En el caso colombiano, desde el Frente Nacional se estableció un esquema de subordinación de los militares al gobierno civil, según el cual los primeros no intervendrían en política a cambio de una autonomía relativa para el manejo de los asuntos de orden público y de otros temas relativos a su campo de acción (Dávila, 1998; Leal, 2006). Sin embargo, las negociaciones de paz con las insurgencias armadas, que comenzaron a principios de los años ochenta, han sido coyunturas de tensión entre civiles y militares, pues en varias oportunidades han provocado el descontento e incluso la oposición de sectores de las FF.AA (Romero, 1998; Ramírez y Restrepo, 1989).

No obstante, las negociaciones de paz entre el gobierno de Juan Manuel Santos (2010-2018) y las Fuerzas Armadas Revolucionarias de Colombia (FARC), desde agosto de 2012, parecen romper con esa tendencia, en la medida en que no se han presentado los ya tradicionales "ruidos de sable", disputas entre el poder militar y el civil en torno a los problemas propios del proceso de paz. Más aún, a pesar de los constantes intentos de la oposición, en cabeza del expresidente y actual senador Álvaro Uribe y su partido el Centro Democrático, por instigar el descontento de las FF.AA. frente al proceso de paz, las instituciones castrenses han adoptado una actitud colaborativa con el gobierno civil. ¿Hasta qué punto esto ha significado una transformación del esquema de relaciones cívico-militares basado en la subordinación y la autonomía relativa?

Este trabajo examina el rol de las FF.AA. en las negociaciones de paz en una perspectiva histórica, con el fin de comprender la situación actual. El esquema de relaciones cívico militares, basado en la subordinación y la autonomía de las FF.AA. frente gobierno civil y establecido desde el Frente Nacional, provoca tensiones en coyunturas como los procesos de paz. El gobierno Santos se enfrentó a la necesidad de articular los militares al proceso de paz en La Habana, enfrentando los intentos de la oposición uribista por ponerlos en contra. Sin embargo, el éxito del gobierno al alcanzar una actitud colaborativa de las FF.AA. respecto de las negociaciones de paz no significa una ruptura con el mencionado esquema de relaciones cívico militares.

Para desarrollar este argumento el trabajo se estructura en tres partes. La primera analiza el esquema de relaciones cívico militares establecido bajo el Frente Nacional. En segundo lugar, se reconstruyen las tensiones entre civiles y militares que tal esquema ha conllevado en las coyunturas de negociación del conflicto armado. Finalmente, se examina el papel de las FF.AA. en el actual proceso de paz.

\section{Autonomía y subordinación}

El Frente Nacional configuró un esquema de relaciones cívico-militares caracterizado por la subordinación de las Fuerzas Armadas (FF.AA.) al poder civil pero, el mismo tiempo, por mantener una considerable autonomía en el manejo de los asuntos de su campo. La persistencia de ese esquema fue posible porque, pese a las tensiones, benefició a ambas partes. El 9 de mayo de 1958, una semana después del último intento de golpe de estado previo al Frente Nacional (1958-1974), el presidente Alberto Lleras Camargo se dirigió a las FF.AA:

\footnotetext{
"Yo no quiero que las Fuerzas Armadas decidan cómo se debe gobernar a la Nación, en vez de que lo decida el pueblo; pero no quiero, en manera alguna, que los políticos decidan cómo se deben manejar las Fuerzas Armadas, en su función, en su disciplina, en sus reglamentos, en su personal. Esas dos invasiones son funestas, pero en ambos casos salen perdiendo las Fuerzas Armadas" (Lleras, 2003, p. 335-336).
}

La interpretación predominante enfatiza la existencia de una subordinación de los militares al gobierno civil y, simultáneamente, el mantenimiento de una considerable autonomía militar en el manejo del orden público (Leal, 2006, p. 20-21; Pizarro, 1995, p. 166; Dávila, 1998, p. 66). Algunos analistas han confrontado esa hipótesis. Para Deas (2003, p. 79), el discurso de Lleras expresó el ideal de subordinación de los militares a los civiles y la autonomía es un mito, puesto que los "ruidos de sable" -las tensiones 
entre ambos- se han resuelto siempre a favor del poder civil y los militares no han tenido los recursos que ambicionaban.

En verdad, existe amplia evidencia para respaldar la tesis de la autonomía. Sin embargo, no hay una explicación convincente de la misma. Tanto los partidarios de dicha interpretación como sus críticos coinciden en explicar la situación por dos factores. Primero, la autonomía de los militares se explicaría por la "indiferencia de parte de los civiles en esos temas" (Deas, 2003, p. 79), su improvisación y despreocupación (Leal, 2006, p. 21), su desconocimiento o falta de voluntad política (Dávila, 1998, p. 192). Segundo, la autonomía se ha visto como un arreglo conveniente únicamente para los militares, sobre todo durante el Frente Nacional, pues les dio capacidad de veto sobre ciertos asuntos (Dávila, 1999, p. 286).

Esta interpretación estaría respaldada porque al encuadrarse el conflicto armado en los esquemas de la Guerra Fría, se habría restado capacidad a los civiles para subordinar a los militares (Andrade, 2012,p. 147). Los militares habrían quedado sin más orientación estratégica que la proveniente de la doctrina contrainsurgente, bajo la influencia de EE.UU., que se apropió en experiencias como la Guerra de Corea y se expresó en la Doctrina de Seguridad Nacional (DSN) (Pizarro, 1995, p. 164). De ahí la ausencia de políticas de defensa y la seguridad definidas por civiles. El Plan Lazo, en los años sesenta fue desarrollado en forma exclusiva por los militares, bajo asesoría norteamericana, y sólo tuvo un correlato civil con la Estrategia Nacional contra la Violencia del gobierno Gaviria (1990-1994).

Al ubicar las causas de la autonomía en el desinterés, la desinformación o la falta de voluntad de los civiles, se descuidan los intereses que llevaron a estos actores a aceptar el arreglo tácito en el que se funda la autonomía, además de suponer unas FF.AA. monolíticas e interesadas únicamente en mantener sus privilegios corporativos. Se asume que los militares no son actores racionales, que su único interés es mantener la autonomía y salvaguardar sus intereses corporativos, cuando no llevar a cabo políticas guerreristas y represivas. Así, el problema de la autonomía se presenta como una paradoja en la que, de acuerdo con Dávila (1998, p. 24), durante el Frente
Nacional se constituyeron en el sostén del régimen de democracia restringida y, al mismo tiempo, en uno de los principales obstáculos para la consolidación de la democracia.

En realidad, la autonomía de los militares se explica por un complejo sistema de incentivos cuya razón de ser es que la mayor parte del tiempo favorece tanto los intereses de los gobiernos y las élites políticas civiles, como de los militares. Es cierto, por ejemplo, que una de las consecuencias más negativas de dicha autonomía articulada a la DSN fue la represión y criminalización de la protesta, cuyas expresiones eran vistas como manifestaciones del "enemigo interno" (Pizarro, 1995, p. 176). Sin embargo, también es cierto que en el interior de las FF.AA. existían distintas lecturas de la forma como se debía dar tratamiento al conflicto social y armado. Por consiguiente, es un error suponer que la autonomía de los militares conducía de forma inexorable a una política represiva y guerrerista y que son las FF.AA. las únicas responsables de la represión en esa época. La autonomía militar y la represión fundada en la DSN se explican mejor porque coincidían con los intereses de las élites políticas bipartidistas. El aparente descuido de las élites políticas respecto de los temas de seguridad y defensa se explica, entonces, porque la autonomía militar era funcional a sus intereses.

Desde esta perspectiva, no existe una paradoja entre la autonomía militar, el mantenimiento del régimen político del Frente Nacional y las dificultades para consolidar la democracia, puesto que impedir la consolidación hace parte del mantenimiento de una democracia restringida y es favorable a los intereses de las élites políticas. Como sostiene Borrero (2006, p. 141), "en Colombia se dio una relación cómoda para las élites civiles y los militares: los militares fungían como muro de contención contra desafíos no sólo revolucionarios, sino aun reformistas, dirigidos contra los intereses de la élite, a cambio de una autonomía institucional relativa". Para los militares, la autonomía era conveniente porque les permitía independencia en el manejo del orden público, era consecuente con la ideología anticomunista de la Guerra Fría y les daba un manejo independiente de los recursos de su sector. 
Aunque los "ruidos de sable" se produjeron por diferencias sobre políticas militares, no siempre los militares adoptaron una visión represiva. Por ejemplo, el general Alberto Ruiz Novoa, veterano de la guerra de Corea que desde 1961 había ideado el Plan Lazo, tenía una visión desarrollista que explicaba la violencia política como una consecuencia de la pobreza (Leal, 2006, p. 65). Su salida del cargo de ministro de Guerra, en enero de 1965, se debió al descontento de gamonales locales de los partidos tradicionales que veían cómo la acción cívico militar disminuía sus clientelas electorales, a los rumores de que con tales políticas el General se preparaba para incursionar en la contienda electoral y a las discusiones con el presidente Guillermo León Valencia, por declaraciones públicas en las que Ruiz instaba al gobierno a desarrollar acciones contundentes contra la pobreza (Dávila, 1998, p. 138-139). Ruiz seguía la línea anticomunista abrazada por las FF.AA., pero en el Ejército existían otras visiones sobre el conflicto. $\mathrm{Su}$ relevo en el ministerio, por el general Gabriel Reveiz Pizarro, significó el reemplazo de la línea "desarrollista" o "sociológica", por una más propensa al ejercicio de la fuerza.

También hubo tensiones por la intervención de los civiles en cuestiones de orden público. Por ejemplo, y aunque se rumoró un intento de golpe de Estado, la destitución del general Álvaro Valencia Tovar de la comandancia de las Fuerzas Militares (FF.MM.), en mayo de 1975, se produjo por desacuerdos con el presidente Alfonso López Michelsen. Primero, por la intervención del presidente para detener la Operación Anorí, cuando el Ejército aparentemente estaba por liquidar al Ejército de Liberación Nacional (ELN) el año anterior; segundo, por la negativa de López a apoyar la acción cívico militar; y tercero, por el desacuerdo de varios generales con la designación del ministro de Guerra y del inspector general de las FFAA. Valencia fue reemplazado por el General Luis Carlos Camacho Leiva, ajeno a la tendencia desarrollista (Leal, 2006, p. 75-76).

Pero también existieron diferencias entre civiles y militares por cuestiones de recursos, cuya gestión era parte de la autonomía de las FF.AA. Por ejemplo, la salida del comandante del Ejército, general Guillermo Pinzón Caicedo, en febrero de 1969, se explica por sus críticas a la intervención del gobierno de Carlos Lleras Restrepo en asuntos de presupuesto. Según Dávila (1998, p. 142), esto generó un rechazo conjunto de la alta oficialidad, que no se produjo con otros "ruidos de sable", como la salida de Ruiz Novoa o la de Valencia Tovar. La preocupación de los militares por su autonomía presupuestal queda confirmada por un informe de la embajada de EE.UU. de la época citado por Richani (2003, p. 83): "los comandantes de brigada de la zona de Bogotá estaban listos para precipitar la caída de [Carlos] Lleras; sin embargo, Pinzón les dijo de modo terminante que él no deseaba que se cayera un gobierno por cuenta suya. No obstante, los generales sí fueron a ver a Lleras y le exigieron [y lograron] una carta de disculpa de Lleras a Pinzón".

Para las élites civiles, la autonomía militar era conveniente porque les permitía estabilizar un régimen en permanente crisis de legitimidad, aislar los problemas de seguridad de la competencia política y librarse de la responsabilidad por la represión y la persistencia del conflicto armado, los cuales recayeron en los militares. El pacto bipartidista, principalmente el reparto paritario de los cargos estatales, deterioró la adscripción ideológica a los partidos y fortaleció los mecanismos clientelistas para asegurar la lealtad (Leal y Dávila, 1991). Así, el reducido tamaño de la "torta burocrática", en relación con las clientelas bipartidistas, produjo una exclusión de sectores sociales emergentes que reclamaban atención estatal y participación política, a lo que se adicionó la expresión del conflicto social en términos de clase social, para conducir a un desborde de la acción política por la vía no institucional. Como argumenta Múnera (1998, p. 145-154), en este momento la hegemonía política empezó a fundamentarse más en la coerción que en el consenso, lo que llevó al manejo militar de la protesta social, apoyado en el uso recurrente del Estado de sitio, que entre otras cosas permitió el juzgamiento de civiles por militares. De esa forma, los gobiernos civiles dejaron en los militares toda responsabilidad por la represión y la persistencia del conflicto armado.

Por ejemplo, la represión a partir del gobierno de Turbay (1978-1982), no puede explicarse únicamente como consecuencia de la autonomía militar. El Decreto Legislativo 1923 de 1978 o Estatuto de Seguridad fue una petición que un sector de las FF.AA. encabezado por el general Camacho Leyva 
hizo al presidente López en diciembre de 1977, luego del Paro Cívico Nacional del 14 de septiembre, para obtener medidas excepcionales para contener el ascenso de la protesta social. López evadió al asunto hasta finalizar su gobierno (Pizarro, 1995, p. 178). En cambio, el empeño de las FF.AA. fue bien recibido por Turbay con el ánimo de contrarrestar el auge del M-19. Por consiguiente, en estricto sentido no es correcto interpretar las relaciones cívico-militares en ese período como una "subordinación mínima" (Dávila, 1998, p. 148), no sólo porque de esa forma se responsabiliza únicamente a los militares por los desmanes permitidos por el Estatuto de Seguridad, sino porque la represión en que se incurrió era funcional al mantenimiento del gobierno civil, en este caso de Turbay.

Ahora bien, el hecho de que la autonomía de las FFAA no condujese a una ruptura del régimen democrático puede explicarse por tres razones. Primero, porque el estado de cosas era suficiente para satisfacer las ambiciones de ciertos sectores militares; los costos de tomarse el poder eran mayores que los beneficios de mantener una subordinación con autonomía y probablemente los "ruidos de sable" tenían un efecto similar al golpe de Estado (Richani, 2003, p. 77). Segundo, las relaciones cívico-militares tenían unas constricciones producto del encuadre del conflicto colombiano en la Guerra Fría y, sobre todo, de la política exterior norteamericana. Finalmente, y tal vez más importante, existía un consenso básico entre las élites civiles, los militares y los EEUU: la política anticomunista.

En efecto, la "doctrina Lleras" implicó una despolitización de las FFAA pero reducida a la prohibición de "deliberar" en asuntos políticos y, fundamentalmente, a una "despartidización": los militares no debían mostrar preferencias por alguno de los partidos tradicionales, Liberal o Conservador. No obstante, eso no implicaba que fuesen apolíticas, pues como afirma Borrero (1990, p. 180), "un ejército sin pensamiento político es un ejército que no conoce su oficio". Más aún, civiles y militares adoptaron una visceral ideología anticomunista, que significó una politización de las FF.AA., no en el sentido de una toma de partido en el proceso político, sino debido a que en el terreno debían resolver la cuestión de quién era parte del "enemigo interno".
Abrazar el anticomunismo permitió articular los intereses de civiles y militares, y eliminar "las contradicciones entre seguridad y orden público, profesionalización y politización, guerra regular y guerra irregular, funciones militares y funciones policiales" (Dávila, 1998, p. 145). Como afirma Leal (2006, p. 71), "la bipolaridad ideológica internacional no era considerada política, pues confrontar el comunismo era sencillamente un deber patriótico". Sin embargo, tal ideología tuvo consecuencias negativas. Primero, el "enemigo interno" se confundió en la práctica con cualquier crítico o adversario del Frente Nacional (Pizarro, 1995, p. 167; Leal, 2006, p. 53); y segundo, impidió realizar una lectura rigurosa del conflicto interno, más allá del esquema de la Guerra Fría, lo que se tradujo, por ejemplo, en pensar que en el interior del Estado podrían existir aliados armados, como los paramilitares, sin importar que cuestionaran el monopolio de la violencia (Borrero, 1990, p. 181-182). En fin, la convergencia entre los intereses civiles y militares en su empeño anticomunista se expresó en el uso casi permanente del estado de sitio para enfrentar los problemas de orden público. Como es sabido, se permitió que la legislación de excepcionalidad fuese recopilada y aplicada a los períodos de normalidad. Así se permitiría el sometimiento a consejos verbales de guerra para aquellos civiles que presuntamente cometieran delitos políticos entre 1965 y 1989 o que las FFAA armaran grupos civiles de autodefensa, entre otros.

En suma, el esquema de relaciones cívico-militares establecido en el Frente Nacional estuvo fundamentado en un sistema de incentivos basado en la subordinación y la autonomía de las FF.AA. cuya persistencia se explica porque beneficia tanto a los civiles como a los militares.

\section{Las FFAA y las negociaciones de paz}

Las tensiones entre civiles y militares tienden a agudizarse en coyunturas como los procesos de paz que ofrecen oportunidades políticas (McAdam, McCarthy y Zald, 1999), como la reconfiguración de las coaliciones, para redefinir los márgenes de autonomía y subordinación. Todos los gobiernos que implementaron políticas de paz desde el de Belisario Betancur (1982-1986) enfrentaron tensiones con los militares, sobre todo cuando no hubo esfuerzos por articular a las FF.AA. en los procesos de paz. 


\section{Betancur (1982-1986)}

Las FFAA se opusieron a las políticas de amnistía y negociación de Betancur. La amnistía benefició a los miembros del M-19, un número importante de los cuales estaba en la cárcel producto de consejos verbales de guerra. Sectores militares culparon al presidente por impedir el triunfo militar sobre esa guerrilla (Leal, 2006, p. 82). Además, la ley de amnistía era ambigua, no exigía la entrega de armas pero duplicaba las penas por su porte ilegal. Esto provocó continuos choques entre guerrilla y Ejército (Ramírez y Restrepo, 1989, p. 97). Aunque en la Comisión de Paz participaron militares retirados -los que se encontraban en servicio activo arguyeron ser no deliberantes- Betancur no fue capaz de articular el sector militar a su propósito de paz. El ministro de guerra de la época, general Fernando Landazábal, pensaba que antes de negociar era necesario atacar las causas objetivas del conflicto, de esa forma el Estado llegaría a la mesa de negociación con mayor legitimidad que la guerrilla, pero Betancur priorizó las negociaciones (Velásquez, 2011, p. 10).

Las FF.AA. obstaculizaron los acuerdos entre gobierno y guerrillas. Las críticas militares arreciaron luego del acuerdo de La Uribe (marzo de 1984), pues hubo mucha dificultad para que la Comisión de Paz verificara la tregua y no hubo claridad sobre el cese al fuego (Velásquez, 2011, p. 11). Las FF.AA. se opusieron abiertamente a la política de paz porque transgredía su autonomía, iba contra el anticomunismo de la DSN y de los privilegios que habían alcanzado durante el gobierno de Turbay (Ramírez, 2003, p. 276-277). Betancur desautorizó a Landazábal cuando este se pronunció en contra del cese al fuego y retomó el discurso de Lleras cuando pidió su renuncia (Borrero, 1990, p. 179). Landazábal renunció en enero de 1984 y Betancur nombró al general Gustavo Matamoros como ministro, quien tuvo una actitud de subordinación pero enfermó y fue reemplazado por el general Miguel Vega Uribe, quien adoptó la misma línea de Landazábal (Velásquez, 2011, p. 11). La tregua firmada con el M-19, en agosto de 1984, se deterioró debido a los hostigamientos del Ejército a sus zonas de concentración, a principios de 1985, y se rompió en mayo de ese año. La reacción de las FF.AA. durante la toma al palacio de justicia por el M-19, el 6 de noviembre de ese año, evidenció la incapacidad del gobierno para mantener su subordinación (Bejarano, 1994, p. 82). No fue ordenada por el presidente, aunque posteriormente asumiera la responsabilidad, incluso se habló de un “cuasigolpe de Estado" (Richani, 2003, p. 78).

Parte de la confrontación entre Betancur y los militares se deriva de la acusación que el procurador profirió el 5 de febrero de 1986 sobre los vínculos de miembros del Ejército con el grupo paramilitar Muerte a Secuestradores, formado por narcotraficantes para impedir secuestros por parte de la guerrilla, en diciembre de 1981. El estamento militar tuvo una reacción corporativa, ordenando destinar un día de salario para la defensa de los miembros implicados y el caso pasó a la justicia penal militar (Ramírez y Restrepo, 1989, p. 116-121).

\section{Barco (1986-1990)}

El gobierno de Barco tuvo mayor capacidad de maniobra, gracias a su esfuerzo por vincular los militares a la política de paz, al crecimiento de los recursos y efectivos de las FF.AA. y la coyuntura de auge del narcoterrorismo, en la que varios militares fueron cuestionados por corrupción (Leal, 2006, p. 91). Según Borrero (1990, p. 191), el gasto militar creció tres veces en pesos constantes. Los efectivos del ejército tuvieron un crecimiento del 55\% (Dávila, 1999, p. 26). Barco privilegió el Plan Nacional de Rehabilitación (PNR) sobre la negociación, haciendo suya la propuesta del ex ministro Landazábal, para quitarle justificación al discurso guerrillero (Velásquez, 2011, p. 12). Cuando el gobierno se abrió a las negociaciones con el M-19, luego del secuestro de Álvaro Gómez por esa guerrilla en mayo de 1988, su Iniciativa de Paz estableció un esquema preciso. El diálogo no podía ser un fin en sí mismo, sino un instrumento para la reincorporación de los alzados en armas a la vida civil; exigía un cese unilateral de hostilidades para iniciar los diálogos y planteaba esquemáticamente las fases en las que debería llevarse a cabo la negociación (Presidencia de la República, 1988).

Dado que el M-19 se desmovilizó en circunstancias muy particulares, las FF.AA. respetaron el proceso, las zonas de concentración y los acuerdos. También aceptaron que las FARC se quedaran en La Uribe, 
incluso luego de la ruptura definitiva de la tregua (Dávila, 1999, p. 297). Aún así, en junio de 1988 el ministro de defensa, General Rafael Samudio, cuestionó el énfasis en la política de paz cuando, a su manera de ver, las FF.MM., podrían derrotar militarmente a la guerrilla. Ese mismo año, hacia el final, el presidente Barco se pronunció para desautorizar declaraciones públicas que hicieran énfasis en la "tierra arrasada", afirmando que la democracia debía ahorrar dolor a los colombianos y eso implicaba usar la persuasión y la negociación. Por eso, anunció el retiro de Samudio y nombró como ministro al general Manuel J. Guerrero Paz (Velásquez, 2011, p. 16). No obstante, la autonomía de los militares pareció proyectarse mediante el fenómeno del paramilitarismo y la llamada "guerra sucia", que fue vista con buenos ojos por algunos miembros de las FF.AA. (Velásquez, 2011, p. 17). La alianza entre sectores de las FF.AA., el narcotráfico y sectores terratenientes representada en el narcoparamilitarismo logró amenazar al sistema político colombiano, de tal forma que para el gobierno Barco la guerrilla dejó de ser la principal preocupación.

\section{Gaviria (1990-1994)}

En este contexto avanzó la propuesta de la Asamblea Constituyente, que se desarrollaría en 1991. En esencia, la Constitución mantuvo el modelo de relaciones cívico militares establecido desde el Frente Nacional, lo cual fue posible por las presiones que sectores militares operaron sobre la Asamblea (Pizarro, 1995, p. 196; Richani, 2003, p. 82), y por el temor entre los constituyentes del M-19 a provocar su ira. Por esa razón, las FF.AA. retuvieron considerable autonomía. la madrugada del 9 de diciembre de 1990, día en que tendrían lugar las elecciones para la Constituyente, se desarrolló la Operación Colombia sobre el campamento donde permanecía el Secretariado de las FARC desde la tregua pactada con Belisario Betancur. Se trató de una decisión autónoma que a posteriori se legitimó en el hecho de que el presidente Gaviria había afirmado que las FF.AA. debían cumplir son su deber y no había territorios vedados para la fuerza pública (Leal, 2006, p. 110).

Según el entonces consejero de seguridad, Rafael Pardo (1996, p. 354), "no hubo ninguna solicitud militar expresa de autorización para realizar operaciones militares en la zona durante el gobierno Barco ni en el de Gaviria”. De acuerdo con Velásquez (2011, p. 19), se trató de un error estratégico, porque desde junio de 1990 la Coordinadora Guerrillera había manifestado su intención de participar en la Constituyente, aunque exigiendo al mismo tiempo que sería sin condiciones. Sin embargo, no se consiguió un acuerdo antes del 9 de diciembre, y las FARC y el ELN arreciaron la ofensiva militar. Pese a eso, aún luego de la elección de Constituyentes se mantenía la posibilidad de su participación, que de cualquier forma no se habría podido decidir por votación. En cambio, se decidió enviar un mensaje según el cual las guerrillas que no se habían desmovilizado quedaban excluidas del pacto fundador de la nueva comunidad política.

A partir de ese momento, el gobierno Gaviria se desenvolvió en torno a dos direcciones: primero, generar una política civil en el campo de la seguridad y la defensa que redujera la autonomía militar, y segundo, debido al fracaso de la Operación Colombia, las FF.MM. se empeñaron en un escalamiento de la confrontación (Leal, 2006, p. 111). Eso terminó por prolongar el conflicto en medio de una escalada de la guerra hacia el final del gobierno de Gaviria (Richani, 2003, p. 78-79). A partir de 1991, y con el fin de corregir el error estratégico, el gobierno impulsaría una serie de medidas para reducir la autonomía militar. Creó el Consejo de Seguridad y Defensa de la Presidencia compuesto en su mayoría por civiles, definió una política de seguridad y defensa -la Estrategia Nacional contra la Violencia-, nombró un ministro de defensa civil y creó la Unidad de Justicia y Seguridad dentro del Departamento Nacional de Planeación para controlar el gasto en seguridad y defensa.

Sin embargo, el proceso estuvo acompañado por la afirmación de la autonomía militar. Así, bajo conmoción interior, en 1992, el gobierno expidió 23 decretos, algunos de los cuales le daban facultades de policía judicial a las FF.MM., lo que fue declarado inexequible por la Corte Constitucional en febrero del año siguiente (Leal, 2006, p. 119). En el mismo sentido, a partir de la Constitución de 1991 hubo un incremento en el pie de fuerza y en el gasto militar, en el marco de lo que el gobierno de Gaviria denominó la "guerra integral" (Pizarro, 1995, p. 200; Granada, 1999, p. 540). Aún así, las relaciones 
entre el gobierno y las FF.AA. no estuvieron libres de tensión. Por ejemplo, en 1993, el traslado de la Corriente de Renovación Socialista a su lugar de concentración para proceder a la desmovilización se vio opacado por el asesinato de dos de sus dirigentes, la Procuraduría señaló que había indicios en contra de los militares (Leal, 2006, p. 123). En junio de 2015 la Corte Suprema de Justicia condenó a dos exintegrantes de las FF.AA. por estos homicidios (El Espectador, 2015c). Por otra parte, las FF.AA. fueron permeadas por la corrupción del narcotráfico (Granada, 1999, p. 579). Al involucrar a los militares en la política de sometimiento a la justicia de los narcotraficantes, se le dio una función policiva, lo que a juicio de Leal (2006, p. 114) mostró que "no son inmunes a la corrupción". Finalmente, la guerra integral no significó una reforma integral de las FF.AA. sino simplemente un conjunto de medidas de orden táctico para mejorar la eficacia en su lucha contra la insurgencia (Pizarro, 1995, p. 204-205).

\section{Samper (1994-1998)}

Bajo el gobierno de Ernesto Samper confluyeron situaciones que permitieron a las FF.AA. retomar la autonomía que había sido cuestionada en el anterior. De acuerdo con Velásquez (2011, p. 22), con el proceso 8000 y la crisis de legitimidad de Samper, que estuvo a la defensiva prácticamente todo el tiempo, se produjo un "vacío estratégico" que permitió a las FARC tomar la iniciativa asestando un total de 17 golpes militares contundentes. Incluso el ministro de defensa Fernando Botero tuvo que renunciar para defenderse judicialmente. Luego hubo otros tres ministros que no fueron capaces de gestionar la crítica situación. El papel de dirección intentó tomarlo el general Harold Bedoya, comandante de las FF.MM., reaccionando al ritmo impuesto por las FARC.

Ante la obstinación del presidente Samper por continuar en su cargo, aún en contra de las presiones de EE.UU., sectores de la clase política acudieron a los militares con la intención de provocar un golpe de Estado, que no avanzó por la torpeza de los civiles y porque los militares estaban desprestigiados ante los golpes de la guerrilla y el avance de los paramilitares (Leal, 2006, p. 21). Debido a la crisis de legitimidad, los militares trataron de encarnar el último bastión de legitimidad estatal (Richani, 2003, p. 79), lo que acarreó tensiones con el gobierno, sobre todo cuando este trató de implementar su política de paz. Samper devolvió la legitimidad de actores políticos a las guerrillas, que pasaron de ser terroristas en el gobierno de Gaviria a potenciales negociadores (Chernick, 1999, p. 45). Su propuesta de "Paz integral y diálogo útil" ubicaba la paz más allá del problema de la confrontación armada: requería desarrollo social, ampliar la democracia y el respeto a los DDHH (García-Peña, 1996, p. 92-94). Pero la baja legitimidad del gobierno hizo casi imposible avanzar en ese sentido.

Transcurridos tres años del gobierno, las FARC se negaban a negociar argumentando su carácter ilegítimo y la necesidad de su renuncia como precondición para iniciar el diálogo. En mayo de 1995 el gobierno acogió la propuesta de esa guerrilla de desmilitarizar La Uribe a fin de desarrollar conversaciones de paz, lo cual desencadenó la oposición de varios altos oficiales en cabeza del general Bedoya (Leal, 2006, p. 140-141). Sin embargo, la débil legitimidad de Samper le restó capacidad de maniobra, de tal manera que tuvo que nombrar a Bedoya comandante de las FF.MM. a finales de 1996. Las gestiones que realizó el gobierno para la liberación de 60 soldados, retenidos por las FARC luego de la toma de la base militar de Las Delicias, el 31 de agosto de 1996, a pesar de que resultaron exitosas, también produjeron una gran tensión entre civiles y militares (Romero, 1998, p. 44). Empero, Samper sólo pudo retirar a Bedoya faltando un año para terminar el período presidencial, el 27 de julio de 1997, cuando normalmente los "ruidos de sable" se resolvían pidiendo la renuncia, que en esta ocasión el General no había aceptado (De Francisco, 1999, p. 523).

Todo ese enfrentamiento se tradujo en la recuperación de la autonomía militar. Así, el presidente incrementó el presupuesto del sector defensa, creó zonas especiales de orden público, permitió la participación de militares en un proyecto de ley para eliminar la Procuraduría Delegada para las Fuerzas Militares, y apoyó el fuero militar sin restricciones, lo que contribuyó a frenar las investigaciones judiciales por violación de derechos humanos en contra de miembros de las FF.AA. (Leal, 2006, p. 146-148). A esto se aunaba el compromiso de sectores de las FF.AA. con el fenómeno del paramilitarismo. 
Durante este gobierno se fomentaron las Convivir, Cooperativas Rurales de Seguridad, que pronto se constituyeron en otro problema dado que formaron fachadas de grupos paramilitares (Romero, 2003, p. 240-250).

\section{Pastrana (1998-2002)}

Según Andrés Pastrana, a su llegada a la presidencia, los altos mandos del Ejército encabezados por el comandante de las FF.MM., general Fernando Tapias, le informaron que la democracia estaba en peligro y estaban "perdiendo la guerra" (Pastrana, 2005, p. 227). La segunda mitad del gobierno de Samper estuvo caracterizada por el escalamiento de la confrontación por parte de las FARC; posteriormente se dijo que se trató de un intento de tránsito de la guerra de movimientos a la de posiciones (Pécaut, 2003, p. 40; Pizarro, 2004, p. 96). Por otra parte, en octubre de 1997 se produjo el "Mandato Ciudadano por la Paz": cerca de diez millones de ciudadanos expresaron su clamor por la paz en las urnas. Por eso no sorprendió la decisión de Pastrana de emprender diálogos con las FARC. Las negociaciones formales iniciaron con la reunión del presidente electo con Manuel Marulanda, comandante de esa guerrilla, el 9 de julio de 1998. Su esquema de negociación introdujo la "zona de despeje", una extensión desmilitarizada de 40.000 kilómetros cuadrados desde el 14 de octubre de 1998, y la negociación en medio de la guerra. Ambos se convertirían en los principales obstáculos del proceso y ocasionaron varias tensiones entre el gobierno y los militares.

Las FARC habían pasado de pedir el despeje del municipio de La Uribe en 1995 a pedir el despeje de 5 municipios (Pécaut, 1999, p. 209). El despeje fue interpretado por algunos sectores como una entrega por pedazos del país a la guerrilla, sobre todo por la total ausencia de normas claras en su manejo. El presidente Pastrana no tuvo en cuenta las recomendaciones de los militares en relación con el proceso de paz, en particular en cuanto a la zona desmilitarizada y el hecho de que los diálogos comprendieran el tema de la reforma de las FF.AA. Éstos pidieron acordar por escrito el término, no desmilitarizar cascos urbanos y mantener las autoridades civiles en las zonas desmilitarizadas (Leal, 2006, p. 185). Las FARC se resistieron a aceptar una verificación internacional, arguyendo en algunos casos que no se habían producido hechos que la hicieran necesaria, "si eso no se había establecido al comienzo, no estaban dispuestos a dejárselo imponer después" (García, 2001, p. 37). Con el paso del tiempo empezaron a utilizar la zona despejada como retaguardia, para mantener recluidos los secuestrados. El primer inconveniente con la zona de distensión se produjo por la permanencia de 130 soldados del batallón Cazadores de San Vicente del Caguán, que fue obligado a retirarse el 15 de diciembre de 1998, lo que ocasionó las primeras discusiones entre el gobierno y el alto mando militar (Velásquez, 2011, p. 26).

El otro punto de discordia fue la vinculación entre miembros de las FF.AA. con el paramilitarismo. Los paramilitares se convirtieron en un serio obstáculo para la implementación de la política de paz, en lo que tiene que ver con los diálogos, tanto con las FARC como con el ELN. Según un estudio del Ministerio de Defensa (2000, p. 10), los grupos paramilitares crecieron como nunca antes en el gobierno de Pastrana, pasando de 3800 integrantes en 1997 a 8150 en 2000. En abril de 1999 se produjo descontento entre el sector militar, encabezado por el ministro de defensa Rodrigo Lloreda, y el gobierno, debido al llamado a calificar servicios de los generales Rito Alejo del Río y Fernando Millán por vínculos con dichos grupos, denunciados por el Departamento de Estado de los EE.UU.

Otro punto de desacuerdo permanente fue la oposición de los militares a la institucionalización del "intercambio humanitario" entre secuestrados por las FARC y prisioneros políticos. La oposición de los militares al proceso de paz fue notoria también en ciertas coyunturas que condujeron a su congelamiento temporal, como en mayo de 2000, debido a la sindicación de las FARC como autores del asesinato de Ana Elvira Cortés con un collar bomba, sindicación que resultó ser falsa. Pero el mayor "ruido de sables" se produjo a propósito de la prórroga a la zona de despeje y la ausencia de mecanismos de verificación en junio de 1999, aunado al descontento de los militares con la reforma al fuero penal militar que haría pasar a la justicia ordinaria los casos de violaciones de $\mathrm{DDHH}$ cometidos por militares. 
El ministro de defensa, Rodrigo Lloreda, manifestó su descontento frente a la intención del gobierno de prorrogar indefinidamente la zona de distensión. Este desacuerdo motivó la renuncia del ministro, que a su vez desencadenó lo que Velásquez (2011, p. 27) considera "la peor crisis en el mando militar en toda la historia del conflicto armado", puesto que 12 generales y 20 coroneles del Ejército pidieron por escrito su retiro, mientras otros 50 oficiales lo hicieron vía telefónica. El general Tapias, comandante de las FF.MM. congeló dichas solicitudes y se hicieron dos reuniones de urgencia, al día siguiente en Cartagena, donde se desarrollaba una cumbre de presidentes, y unos días después en Melgar, entre el presidente y todos los generales de las FFMM. El descuido del gobierno por articular los militares a la política de paz resalta en el hecho de que era la primera reunión de este tipo.

Sin embargo, a partir de allí las relaciones entre gobierno y FF.AA. dieron un giro importante. El presidente prometió reconsiderar sus planes para reducir los beneficios de retiro de los militares, las reservas pensionales, la justicia penal militar, y consultarles de forma más cercana las políticas de paz. En particular, modificó la reforma al fuero penal militar de tal manera que se definían la tortura, la desaparición forzada y el genocidio como las únicas violaciones de DDHH que no podía conocer la justicia militar, reforma que más tarde sería declarada inconstitucional (León, 2011). Así pues, como en otras circunstancias, la autonomía militar se hizo sentir para favorecer recursos para su campo (Richani, 2003, p. 80). A esto se adicionó la reforma militar impulsada con los recursos del Plan Colombia. Aprobado en EE.UU. el 5 de junio de 2000, el Plan Colombia explicó el conflicto por la existencia del narcotráfico, por ello introdujo una visión distinta de la guerrilla y de la solución del conflicto. A diferencia del estatus político que Pastrana les había conferido, el Plan los concebía como delincuentes y, por consiguiente, más que negociaciones su tratamiento debía ser policivo y militar (Romero, 2001, p. 237). La mayor cantidad de recursos del Plan Colombia fue destinada al fortalecimiento de las FF.AA., en un principio para mejorar su eficacia en el combate contra los cultivos ilícitos, pero luego su intención antinarcóticos se confundió con su esfuerzo contrainsurgente (Pizarro, 2004, p. 258). Esos recursos permitieron desarrollar la reforma militar y la modernización tecnológica y logística de las FFAA más importante en la historia del país y limar las asperezas entre el gobierno y los militares.

\section{Uribe (2002-2010)}

Con la terminación de los diálogos del Caguán el 20 de febrero de 2002, la opinión pública se volcó hacia un tratamiento militar que fue encarnado por el disidente liberal Álvaro Uribe (Guedán y Ramírez, 2005, p. 34). En lugar de apostarle a la negociación con la insurgencia, Uribe le apostó a la Política de Seguridad Democrática (PSD), que continuaba con la reforma de las FF.AA. emprendida por Pastrana. Con ese empeño, hizo todos los esfuerzos necesarios por encuadrar el conflicto armado colombiano en el marco de la "guerra contra el terrorismo", emprendida por EE.UU. luego del 11 de septiembre de 2001 (Pécaut, 2003, p. 102-104). Como consecuencia lógica, se negó a reconocer que en Colombia existía un conflicto armado. En su discurso, lo que existía era una "amenaza terrorista" contra un Estado legítimo. Así, si bien en distintos momentos el gobierno ofreció la posibilidad de iniciar diálogos con la insurgencia bajo la condición de cese al fuego unilateral, en la práctica nunca reconoció en ellos un actor político.

Fundada en el discurso antiterrorista, la PSD actualizó la DSN. De hecho, dicha política se caracterizó por la ausencia de planes de seguridad ciudadana, bajo el supuesto de que la seguridad del Estado es igual a la seguridad del ciudadano (Leal, 2006, p. 26). El enemigo interno, igual de difuso que el comunismo y por tanto tan fácil de confundir con cualquier crítico del gobierno como aquél, pasó a ser el "terrorismo". En distintas circunstancias el propio presidente se encargaría de descalificar cualquier intento de crítica a su gobierno tildándolo de terrorismo o auxiliador del mismo. De hecho, la PSD estaba orientada a la articulación de la sociedad a un propósito antiterrorista, que ponía en cuestión la distinción entre combatientes y no combatientes con figuras como la red de informantes, dependiente de las FF.AA., y los soldados campesinos (Gallón, 2005, p. 128).

La PSD apuntaló la reforma militar, aunque se limitó a sus aspectos operativos y tácticos, y condujo a reducir la sensación de inseguridad en algunos ámbitos, acompañada de una amplia estrategia de 
comunicación política con campañas como "vive Colombia, viaja por ella", con la cual las FF.AA. se encargaban de custodiar las vías principales y los turistas en determinados días. Según Atehortúa (2007, p. 77) hubo un crecimiento considerable del pie de fuerza militar, de alrededor de 50,1\%. Este esfuerzo, aunado a las mejoras en tecnologías y la adquisición de equipos de transporte permitieron que las FF.AA. dejaran de ser reactivas y tomaran la iniciativa. Por ejemplo, crecieron las brigadas móviles y se ensayaron estructuras operativas como los comandos conjuntos, lo que permitió asegurar una mayor velocidad y cobertura espacial (Borrero, 2006, p. 117-119). Algunos logros de la PSD fueron el obligar a un repliegue táctico de la guerrilla, la presencia de la fuerza pública en todos los municipios del país, el descenso en indicadores relevantes como secuestros masacres, hurtos y homicidios, y en general un aumento en la percepción de seguridad por parte de la población (Atehortúa, 2007, p. 52).

No obstante, el esquema de relaciones civiles-militares no se transformó en lo sustancial. La legitimidad de Uribe dependía del desempeño de la PSD y, por consiguiente, de las FF.AA. Eso explica el que su gobierno se rehusara a implementar reformas profundas en las instituciones castrenses (SchultzeKraft, 2012, p. 421; Ruiz, Illera y Manrique, 2006, p. 214). Por consiguiente, predominó lo que podría denominarse una "subordinación desinstitucionalizada". Por una parte, más que a la autoridad civil, existió una subordinación a la persona del presidente Uribe, que él mismo se encargó de construir, por ejemplo, cuando en sus Consejos Comunitarios y otros escenarios se saltaba la cadena de mando para regañar públicamente o inquirir directamente a los subalternos por determinados problemas (Leal, 2006 p. 240; Velásquez, 2011, p. 29; Atehortúa, 2007, p. 84).

Por otra parte, una consecuencia de esa subordinación desinstitucionalizada fue el incremento de la autonomía militar. Así puede interpretarse, por ejemplo, la salida de la primera mujer en desempeñarse como ministra de Defensa, Marta Lucía Ramírez, en marzo y abril de 2003. La ministra adoptó decisiones orientadas a la modernización en la gestión y el manejo de los recursos, como el nombramiento en la Secretaría General del ministerio de una funcionaria civil, cuando ese cargo tradicionalmente era ocupado por un General y el control centralizado del gasto (Leal, 2006, p. 238). La posterior salida del cargo de Marta Lucía Ramírez pone en evidencia que, pese a la cercanía con el presidente, las FF.AA. mantuvieron un poder de veto sobre ciertos asuntos. Los problemas más graves de la política de seguridad democrática vinieron de la mano de la desinstitucionalización que, pese al debilitamiento militar de la guerrilla, fueron en contra de la legitimidad del Estado, tales como los "falsos positivos", el escándalo por las escuchas ilegales del Departamento Administrativo de Seguridad, la "parapolítica", las detenciones arbitrarias producto de la operación de la "red de informantes" y la falta de efectividad de las FF.AA. para controlar la contrarreforma agraria de los terratenientes ligados a los paramilitares (Velásquez, 2011, p, 36-37).

Los constantes llamados de Uribe a acabar con las guerrillas a sangre y fuego, aunados a la estigmatización de cualquiera que osase criticar sus políticas con el mote de "terrorista", crearon incentivos para la ampliación de la autonomía militar. Un error de la política de seguridad democrática fue la presión por resultados, lo que llevó a desconocer normas básicas del Estado de Derecho y a los "falsos positivos", las ejecuciones extrajudiciales con el objetivo de hacer pasar civiles por combatientes dados de baja (Atehortúa, 2007, p. 73). Otros episodios recordaron la corrupción en la que incurrieron sectores de las FF.AA. tras su inmersión en la guerra contra las drogas en los años ochenta (Granada, 1999, p. 579). En Guaitarilla Nariño, en 2004, cuatro civiles y siete policías fueron asesinados por militares que, al parecer, iban a apoderarse de un cargamento de cocaína. En Jamundí Valle, en 2006, fueron diez los policías y un civil asesinados en un enfrentamiento con militares que presuntamente estaban aliados a narcotraficantes (Schultze-Kraft, 2012, p. 414).

En fin, una constante en todos los procesos de paz desde principios de los años ochenta es el descontento de sectores militares. Las políticas de paz han producido tensiones en las relaciones entre civiles y militares siempre que éstos últimos han encontrado oportunidades políticas para mantener o ampliar su autonomía. 


\section{Las FF.AA. y el proceso de paz en La Habana}

Los gobiernos que han intentado articular los militares con sus políticas de paz, como el de Barco o el de Pastrana, han presentado menos tensiones en las relaciones cívico militares, a cambio de aumentar o mantener la autonomía de las FF.AA., en comparación con aquellos que se han esforzado por menguarla, como el de Betancur. La actitud colaborativa de las FF.AA. con el proceso de paz del gobierno Santos no rompe con esta tendencia, en la medida en que ha supuesto el mantenimiento de la autonomía propia del esquema de relaciones cívico militares establecido bajo el Frente Nacional. Sin embargo, como se verá, el actual proceso de paz presenta, cuando menos, tres novedades. Primero, se trata de uno de los gobiernos que más ha hecho por articular las FF.AA. a su política de paz, llegando incluso a vincular miembros activos $\mathrm{y}$ en retiro a la mesa de negociaciones, pero esto no ha conseguido mermar las críticas de varios sectores militares. Segundo, es el proceso de negociación que más ha avanzado hacia un acuerdo definitivo para acabar el conflicto con las FARC, lo cual plantea un escenario de eventual postconflicto que es totalmente distinto al que las FF.AA. enfrentaron en anteriores negociaciones. Y tercero, la oposición del sector uribista ha disputado con el gobierno el intento de articular a los militares descontentos en contra del proceso de paz.

En efecto, el legado del gobierno Uribe ha afectado, tanto como la oposición que hoy encarna el expresidente, el proceso de paz. Si bien Santos fue electo en 2010 como continuador de las políticas de Uribe, pronto su interés se centró en empezar negociaciones de paz, lo cual supuso un diagnóstico que más allá de la "amenaza terrorista" empezó por concebir la existencia de un conflicto armado y por reconocer en la insurgencia un interlocutor político. Tal situación, aunada al hecho de que las instituciones castrenses llevaban diez años pensando que luchaban contra delincuentes y no contra rebeldes políticos (Orozco, 1992) tornó muy complicadas las relaciones entre el gobierno y sectores de las FF.AA., sobredimensionada por la intención de la oposición uribista de articularlas a su bando. Sin embargo, la vinculación activa de las FF.AA. al proceso de paz disminuyó las tensiones hasta conseguir una actitud colaborativa.
En momentos álgidos del proceso de paz, hubo evidencias de la existencia de sectores militares que desconfiaban de las negociaciones y de lo que significaría, en términos de justicia y pérdida de autonomía, por ejemplo, un eventual postconflicto. Si bien siempre hubo organizaciones de oficiales retirados, no tuvieron el protagonismo que hoy tiene la Asociación Colombiana de Oficiales en Retiro de las Fuerzas Militares (ACORE), con alrededor de 3000 integrantes. Su presidente, el General (r) Jaime Ruiz Barrera, fue particularmente crítico del proceso de paz e incluso llegó a acusar a Santos de humillar a las FF.AA. (El Espectador, 2015a). Pero la falta de legitimidad de Santos no sólo tocó a los oficiales retirados. Una muestra de descontento tuvo lugar el 19 de abril de 2015 cuando el presidente participaba de una carrera en beneficio de los héroes militares y fue abucheado, hecho que ocurrió justo después del ataque de las FARC en el Cauca, que dejó como resultado 11 bajas en el Ejército.

Al principio la estrategia gubernamental no parecía ajustarse a la situación, al manejar un doble discurso. Mientras Santos hizo de la paz el nodo articulador de sus políticas, su ministro de defensa, Juan Carlos Pinzón, quien asumió en agosto de 2011 en reemplazo de Rodrigo Rivera y se mantuvo en el cargo hasta junio de 2015, se encargó de manejar una retórica belicista más propia de la oposición uribista. El 23 de mayo de 2012, Santos (2012) invocó el discurso de Lleras Camargo en el marco de la Cátedra Colombia en el Teatro Patria, en una alocución para tranquilizar a los militares frente al proceso de paz. Entre otras cosas, allí presentó a las FF.AA. como artífices de la paz, erigida en la victoria verdadera, y propuso reformas orientadas a favorecer una justicia imparcial y mejoras en los servicios de bienestar social. Sin embargo, el ministro Pinzón en diversas oportunidades adoptó la posición de vocero de los sectores más reacios de las FF.AA. frente al proceso de paz, lo que llevó a contrariar los mensajes del Presidente. Una situación compleja producto de ese desencuentro se produjo durante la primera crisis del proceso de paz a raíz del secuestro y posterior liberación del general Rubén Darío Alzate por parte de las FARC, en noviembre de 2014. Mientras Santos se comprometió con los países garantes del proceso a suspender las operaciones de rescate para facilitar la liberación, el Ejército lanzó una operación de rescate 
que tardó varios días en suspenderse definitivamente (Lewin, 2014).

Ahora bien, el problema más delicado fue el permanente intento de la oposición en cabeza de Uribe por politizar a las FF.AA. en contra del proceso de paz. Uribe parecía seguir teniendo una relación privilegiada con sectores militares activos. Eso se evidencia en las múltiples ocasiones en que recibió información de inteligencia y contrainteligencia militar que comprometía el proceso de paz, antes de que la reciba el propio gobierno. En abril de 2013 reveló en una red social las coordenadas de los vuelos que llevarían a Cuba algunos negociadores de las FARC (Semana, 2013). Fue el primero en revelar la noticia sobre el secuestro del General Alzate el 16 de noviembre de 2014, hecho que generó una suspensión de los diálogos por parte del gobierno (Semana, 2014c). A fines de junio de 2015 el hoy senador reveló información de contrainteligencia militar según la cual las FARC estarían preparando un "plan pistola" en contra de altos oficiales de las FF.AA. y sus familiares (Semana, 2015b). Esos hechos, a su vez, no serían preocupantes si no existiesen otros escándalos por escuchas ilegales por parte de instancias de inteligencia militar, como las que salieron a la luz pública en febrero de 2014 a raíz de la fachada Andrómeda, operación legalmente autorizada pero con prácticas ilegales de interceptación de comunicaciones a los negociadores del gobierno en La Habana y a personalidades de la oposición de izquierda (Semana 2014a y 2014b).

Las "chuzadas" ilegales tuvieron otro capítulo a principios de mayo de 2014, cuando en plena campaña presidencial fue capturado un supuesto "hacker", asesor de la campaña del candidato uribista por el partido Centro Democrático, Oscar Iván Zuluaga, por delitos similares. En enero de 2015 una comisión investigadora de los casos Andrómeda y Sepúlveda condujo a la separación de sus cargos a más de 30 integrantes de las FFAA, entre quienes le habrían entregado información confidencial al asesor de la campaña de Zuluaga (Semana, 2015a). En realidad, la campaña presidencial se convirtió en una disputa entre el candidato-presidente Santos, quien se encontraba en disputa por la reelección, y el uribismo por ganar el favor de las FF.AA. Cinco policías fueron destituidos por participar en política haciendo campaña a favor del candidato Zuluaga. El uribismo incluyó entre sus huestes a la señora Tania Vega de Plazas, senadora por la lista del Centro Democrático y esposa del Coronel detenido Alfonso Plazas Vega, quien hacía campaña con las familias de militares en contra del proceso de paz y a favor de Zuluaga, particularmente en las asociaciones de militares en retiro, muchas veces con la presencia de Uribe y Zuluaga. El candidato uribista proponía medidas especiales para los militares, como la excarcelación para quienes estaban detenidos sin condena por falsos positivos, un alto tribunal temporal para revisar condenas militares y aumentar el salario de soldados y policías (Arenas, 2014).

La otra gran crisis del proceso de paz se produjo en abril de 2015, después de la emboscada de las FARC en el Cauca que dejó 11 soldados muertos. Uribe se dedicó a hacer proselitismo mediático visitando a los soldados que habían quedado heridos y promovió un proyecto de ley para que los militares sólo pagaran 5 años de cárcel por crímenes cometidos en servicio, justificado en la gratitud hacia los militares y en el hecho de que, según él, no se pueden igualar con los "terroristas", lo que en realidad era más un mensaje de apoyo a los militares que un proyecto con posibilidades de ser aprobado (Arenas, 2015). En fin, la disputa por el apoyo de los militares llegó hasta el punto de que la cúpula de las FF.AA. pidió que no se los utilizara como parte de la política, ante las recriminaciones entre gobierno y oposición luego del ataque en el Cauca (Semana, 2015d).

El gobierno Santos desplegó ingentes esfuerzos para articular políticamente a los militares y disputar el intento de la oposición uribista por ponerlos de su lado en la crítica del proceso de paz que finalmente fueron exitosos. Sin embargo, la actitud colaborativa de las FF.AA. no se ha traducido en una transformación del esquema de relaciones cívico militares basado en la subordinación y la autonomía, sino que incluso a aumentado esta última. En noviembre de 2011, la periodista Juanita León afirmaba: "Santos les está dando a los militares lo que Uribe nunca se atrevió a concederles". Para entonces, el presidente había presentado al Congreso tres proyectos de ley en beneficio de los militares. Uno de defensa técnica para que el Estado costeara abogados para militares implicados en cualquier caso judicial a nivel nacional 
e internacional, con el objetivo de contrarrestar la "guerra jurídica" en su contra; el "marco jurídico para la paz", una ley para juzgar a los actores del conflicto por crímenes cometidos en guerra, y la reforma del fuero penal militar, que inicialmente se contempló como parte de la reforma de la justicia con el objetivo de que todos los crímenes que implicaran violaciones a los DDHH fuesen juzgados por tribunales militares, incluyendo los "falsos positivos" (León, 2011).

Santos respondió a la petición de participación de los militares en la mesa de negociación que hizo ACORE nombrando al General (r) Jorge Enrique Mora Rangel como parte del equipo negociador. También incluyó al exdirector de la Policía, General (r) Oscar Naranjo (International Crisis Group [ICG], 2012, p. 22). El gobierno incluso motivó la participación de más militares, esta vez activos, en el proceso de paz. Así, el 22 de agosto de 2014 se revelan los nombres de los integrantes de las FF.AA. que conformarían una subcomisión para el fin del conflicto en La Habana. Del mismo modo, el 3 de marzo de 2015 cinco generales y un almirante viajan a La Habana para estudiar las posibilidades de un cese al fuego bilateral, como resultado se acuerda el inicio de un proceso de desminado conjunto, entre guerrilleros y militares.

Un tema trascendental para los militares en la negociación del conflicto es la justicia y los criterios que se seguirán para establecer su responsabilidad en violaciones de los DDHH y del DIH. En junio de 2012 un tribunal de Bogotá sentenció al Coronel (r) Luis Alfonso Plazas Vega a 30 años de prisión por la desaparición forzada de once personas durante la retoma del palacio de justicia, en noviembre de 1985. Este hecho se constituyó en un antecedente problemático para los militares, quienes se enfocaron en rechazar los tribunales civiles, opinión magnificada por oficiales en retiro, el expresidente Uribe y sus adeptos (ICG, 2012, p. 22). Para menguar la intranquilidad en las filas castrenses, el presidente Santos procuró en distintos momentos la ampliación del fuero penal militar. El 13 de junio de 2013 el Congreso aprobó la primera reforma al fuero penal militar, que meses más tarde, en octubre, sería declarada inconstitucional por vicios de procedimiento. El debate estuvo atravesado por la discusión sobre si los "falsos positivos" serían juzgados por tribunales militares. El 5 de octubre de
2014 el ministro de defensa presentó otro proyecto para reformar el fuero penal militar, el cual fue aprobado definitivamente el 11 de junio de 2015. La reforma no consiguió la aprobación de los militares. ACORE rechazó la iniciativa porque el proyecto fue recortado en el Congreso y, en su perspectiva, tal como se aprobó no brindaba seguridad jurídica a los combatientes (El Espectador, 2015b).

En suma, frente al problema de la justicia el gobierno ha hecho todo lo posible para apaciguar los temores de los militares, así se evidenció luego de la vehemente defensa del presidente tras el informe sobre "falsos positivos" de Human Rights Watch (HRW) que comprometía a 16 generales en estos crímenes, entre ellos a los comandantes del Ejército y las FFMM, en junio de 2015. El informe sostiene que no es posible que una práctica sistemática y generalizada que llevó a más de 3000 ejecuciones extrajudiciales, alrededor del $20 \%$ de las bajas, se desarrollara sin su conocimiento (El Espectador, 2015d). Santos, durante una ceremonia de posesión del nuevo ministro de defensa, Luis Carlos Villegas, rechazó tajantemente el informe de HRW; afirmó que la Fiscalía y la Procuraduría no tenían investigaciones contra los generales implicados que se desempeñaban en altos cargos; concluyó declarando que defendería a las FF.AA. hasta "la tumba" (Semana, 2015c). En la práctica, Santos adoptó una actitud similar a la que hubiese tenido el gobierno Uribe, asumiendo que llamar la atención sobre un problema es desprestigiar las instituciones en lugar de ver las denuncias como una oportunidad para robustecerlas.

El 23 de septiembre de 2015, el gobierno y las FARC consiguieron un acuerdo sobre el punto considerado más problemático en la agenda de las negociaciones de paz. El acuerdo sobre justicia transicional, restaurativa y reparadora, crea una jurisdicción especial para los crímenes cometidos en el marco del conflicto armado, que cobijaría a todas las partes, los integrantes de la guerrilla y los agentes de la sociedad civil y del Estado, incluyendo los militares. A principios de julio el presidente Santos realizó un cambio en la cúpula militar, nombrando al general Alberto Mejía como comandante de las FF.MM. De acuerdo con Lewin y León (2015), si bien el cambio era rutinario, debido a la formación y trayectoria de los oficiales designados no solo se 
trataba de acercar más las FF.AA. al gobierno, sino de prepararlas para el eventual postconflicto. Por esa razón, frente al acuerdo sobre la justicia y al acuerdo final dado a conocer en agosto de 2016, la actitud del alto mando fue de colaboración, incluso aunque sectores del uribismo criticaron el hecho de que la Justicia Especial para la Paz "igualara" a los militares con los guerrilleros. En lugar de expresar opiniones políticas, al margen de las directrices del Gobierno Nacional, el general Mejía anunció desde finales de 2015 que las FF.AA. pondrían en marcha una reestructuración de la doctrina militar (El Espectador, 2015e). Sin embargo, el hecho de que tal anuncio lo haga la máxima autoridad de las FF.MM. en lugar del Gobierno muestra hasta qué punto estas instituciones conservan su autonomía.

\section{Conclusiones}

El esquema de relaciones cívico-militares que se estableció a principios del Frente Nacional, basado en la subordinación de las FF.AA. al poder civil a cambio de cierto nivel de autonomía en el manejo de su sector, se ha mantenido incluso dos décadas después de la reforma constitucional de 1991, en parte debido a la persistencia del conflicto armado interno. Dicho esquema está formado por un sistema de incentivos que hace que para los militares sea menos costoso aceptar la subordinación a cambio de autonomía que cambiar el régimen democrático y, a su turno, los civiles durante la mayor parte del tiempo han dejado la responsabilidad sobre el manejo del orden público y la guerra en los militares.

Sin embargo, el esquema provoca tensiones en las relaciones cívico-militares cuando existen oportunidades políticas para ampliar o reducir la autonomía militar, como la reconfiguración de coaliciones políticas que se producen con la implementación de procesos de negociación con la insurgencia. Si bien en todos los procesos de paz, que comenzaron en 1982, las FF.AA. han mostrado su crítica, cuando no su abierta oposición, el actual proceso de paz en La Habana plantea un contexto muy distinto que afecta el posicionamiento que frente a él pueden adoptar los militares descontentos.

El proceso de paz tiene lugar cuando las instituciones castrenses disfrutan de los mayores índices de legitimidad en su historia y cuando se implementa el esquema de negociación que más ha avanzado en la consecución de un acuerdo final. Los temores de ciertos sectores militares se vieron sobredimensionados con el permanente intento de la oposición uribista por articularlos en contra de las negociaciones. Los ingentes esfuerzos del gobierno Santos por tranquilizar a los sectores descontentos han redundado en su compromiso con el proceso de paz. Sin embargo, el costo de ese compromiso parece ser el mantenimiento del esquema de relaciones cívico militares basado en la subordinación y la autonomía.

\section{Referencias bibliográficas}

Andrade O. (2012). Relaciones cívico-militares en Colombia. Apuntes para un estado del arte. Revista de Análisis Internacional, 6, 145-171.

Arenas, N. (2014). La voz del uribismo con los militares. Extraído el 12 de Junio de 2014 desde http://asillavacia.com/historia/thania-militares-47867

Arenas, N. (2015). Los cariñitos de Uribe con los militares. Extraído el 22 de Abril de 2015 desde http://lasillavacia.com/historia/los-carinitos-de-uribe-con-los-militares-50056

Atehortúa, A. (2007). Las banderas del presidente Uribe. Medellín: La Carreta.

Bejarano, J. (1994). La política de paz durante la administración Barco. En M. Deas y C. Ossa (coords.), El gobierno Barco: política, economía y desarrollo social en Colombia 1986-1990 (pp. 79-106). Bogotá: Fedesarrollo-Fondo Cultural Cafetero.

Borrero, A. (1990). Militares, política y sociedad. En F. Leal y L. Zamosc (eds.), Al filo del caos. Crisis política en la Colombia de los años 80 (pp. 175-192). Bogotá: Tercer Mundo-Iepri.

Borrero, A. (2006). Los militares: los dolores del crecimiento. En F. Leal (ed.), En la encrucijada. Colombia en el siglo XXI (pp. 113-146), Bogotá: Uniandes-Norma. 
Chernick, M. (1999). La negociación de una paz entre múltiples formas de violencia. En F. Leal (ed.), Los laberintos de la guerra. Utopias e incertidumbres sobre la paz (pp. 3-57). Bogotá: Tercer Mundo-Universidad de los Andes.

Dávila, A. (1998). El juego del poder. Historia, armas y votos. Bogotá: Cerec-Universidad de los Andes.

Dávila, A. (1999). Ejército regular, conflictos irregulares: la institución militar en los últimos 15 años. En M. Deas y M. Llorente (comps.), Reconocer la guerra para construir la paz (pp. 283-345). Bogotá: Uniandes-Cerec-Norma.

De Francisco, G. (1999). La fuerza pública y la estrategia para enfrentar el fenómeno guerrillero. En M. Deas y M. Llorente (comps.), Reconocer la guerra para construir la paz (pp. 475-536). Bogotá: Uniandes-Cerec-Norma.

Deas, M. (2003). Perspectiva histórica de las relaciones cívico-militares en Colombia. En F. Cepeda (ed.), Las relaciones cívico-militares en tiempos de conflicto armado ( $\mathrm{pp}$. 77-85). Bogotá: Fundación Ideas para la Paz.

El Espectador, (2015a). Los militares (r) dicen que el presidente Santos los humilló. Extraído el 27 de Abril de 2015 desde http://www. elespectador.com/noticias/politica/los-militares-r-dicen-el-presidente-santos-los-humillo-video-557264

El Espectador, (2015b). A favor y en contra del fuero militar. Extraído el 9 de Junio de 2015 desde http://www.elespectador.com/noticias/ politica/favor-y-contra-del-fuero-militar-articulo-565437

El Espectador, (2015c). Condenan a militares por muerte de negociadores de paz. Extraído el 24 de junio de 2015 desde http://www. elespectador.com/noticias/judicial/condenan-militares-muerte-de-negociadores-de-paz-articulo-568386
El Espectador, (2015d). Informe sobre falsos positivos no pretende desprestigiar a las FF.AA.: HRW. Extraído el 24 de junio de 2015 desde http://www.elespectador.com/ noticias/judicial/informe-sobre-falsos-positivos-no-pretende-desprestigia-articulo-568309

El Espectador, (2015e). Comandante del Ejército anuncia revisión total de la doctrina militar en Colombia. Extraído el 26 de septiembre de 2015 desde http://www.elespectador. $\mathrm{com} /$ noticias/judicial/comandante-del-ejercito-anuncia-revision-total-de-doctr-articulo-588624

Gallón, G. (2005). Los riesgos de una desenfocada política antiterrorista en Colombia. En M. Cárdenas (comp.), La reforma politica del Estado en Colombia: una salida integral a la crisis (pp. 121-153). Bogotá: Cerec-Fescol.

García-Peña, D. (1996). El gobierno colombiano y su política de paz. En Paz y Guerra en conflictos de baja intensidad. El caso colombiano. Memorias del encuentro colombo español (pp. 88-97). Bogotá: Atípicos.

García, M. (2001). Veinte años buscando una salida negociada: aproximación a la dinámica del conflicto armado y los procesos de paz en Colombia 1980-2000. Controversia, 174, 11-41.

Granada, C. (1999). La evolución del gasto en seguridad y defensa en Colombia. En M. Deas y M. Llorente (comps.), Reconocer la guerra para construir la paz (pp. 537-597). Bogotá: Uniandes-Cerec-Norma.

Guedán, M. y Ramírez, R. (2004). Colombia, la guerra de nunca acabar. Madrid: Trama.

International Crisis Group, (2012). Colombia: ¿Por fin la paz?. Informe sobre américa Latina (Bogotá), 45.

Leal, F. (2006). La inseguridad de la seguridad. Colombia 1958-2005. Bogotá: Planeta. 
Leal, F. y Dávila, A. (1991). Clientelismo. El sistema político y su expresión regional. Bogotá: Tercer Mundo.

León, J. (2011). Santos les está dando a los militares lo que Uribe nunca se atrevió a concederles. Extraído el 16 de Noviembre de 2011 desde http://lasillavacia.com/historia/santos-le-esta-dando-los-militares-lo-que-uribe-nunca-se-atrevio-concederles-29663

Lewin, J. (2014). Los militares, humillados por secuestro y liberación de Alzate. Extraído el 24 de Noviembre de 2014 desde http:// lasillavacia.com/historia/los-militares-humillados-por-secuestro-y-liberacion-de-alzate-49135

Lewin, J. y León, J. (2015). Santos alinea defensa para la paz. Extraído el 26 de agosto de 2015, de: http://lasillavacia.com/historia/ santos-alinea-defensa-para-la-paz-50701

Lleras, A. (2003). [1958] "Las Fuerzas Armadas". En F. Cepeda (Ed.), Las relaciones cívico-militares en tiempos de conflicto armado (pp. 329-342). Bogotá: Fundación Ideas para la Paz.

McAdam, D., McCarthy, J. y Zald M. (1999). Oportunidades, estructuras de movilización y procesos enmarcadores: hacia una perspectiva sintética y comparada de los movimientos sociales. En D. McAdam, J. McCarthy y M. Zald (Eds.), Movimientos sociales: perspectivas comparadas. Oportunidades politicas, estructuras de movilización y marcos interpretativos culturales (pp. 21-46). Madrid: Itsmo.

Ministerio de Defensa Nacional. (2000). Los grupos ilegales de autodefensa en Colombia. Bogotá: Ministerio de Defensa.

Múnera, L. (1998). Rupturas y continuidades. Poder y movimiento popular en Colombia 1968-1988. Bogotá: Universidad Nacional de Colombia-Cerec.
Orozco, I. (1992). Combatientes, rebeldes y terroristas. Guerra y derecho en Colombia. Bogotá: Universidad Nacional de ColombiaTemis.

Pardo, R. (1996). De primera mano. Colombia 1986-1994: entre conflictos y esperanzas. Bogotá: Norma-CEREC.

Pastrana, A. (2005). Antecedentes y perspectivas de la seguridad democrática. En A. Rangel (comp.), Sostenibilidad de la seguridad democrática. Bogotá: Fundación Seguridad y Democracia (pp. 225-238).

Pécaut, D. (1999). Estrategias de paz en un contexto de diversidad de actores y factores de violencia. En F. Leal (ed.), Los laberintos de la guerra. Utopías e incertidumbres sobre la paz (pp. 193-242). Bogotá: Tercer Mundo-Universidad de los Andes.

Pécaut, D. (2003). Midiendo fuerzas. Balance del primer año del gobierno de Álvaro Uribe Vélez. Bogotá: Planeta.

Pizarro, E. (1995). La reforma militar en un contexto de democratización política. En F. Leal (comp.), En busca de la estabilidad perdida. Actores políticos y sociales en los años noventa (pp. 159-208). Tercer Mundo-Iepri.

Pizarro, E. (2004). Una democracia asediada. Balance y perspectivas del conflicto armado en Colombia. Bogotá: Norma.

Presidencia de la República de Colombia. (1988). Iniciativa para la paz. Bogotá: Presidencia de la República.

Ramírez, S. (2003). El proceso de paz de Belisario Betancur. En M. Medina y E. Sánchez (comps.), Tiempos de paz. Acuerdos en Colombia 1902-1994 (pp. 277-284). Bogotá: IDCT.

Ramírez, S. y Restrepo, L. (1989). Actores en conflicto por la paz. El proceso de paz durante el gobierno de Belisario Betancur 1982-1986. Bogotá: Siglo XXI-CINEP. 
Richani, N. (2003). Sistemas de guerra. La economía politica del conflicto en Colombia. Bogotá: Iepri-Planeta.

Romero, M. (1998). Tendencias del conflicto armado e iniciativas de paz. Bogotá: ESAP.

Romero, M. (2001). La nueva internacionalización del conflicto y los procesos de paz. En J. Estrada (ed.), Plan Colombia. Ensayos críticos (pp. 235-277). Bogotá: Universidad Nacional de Colombia.

Romero, M. (2003). Paramilitares y autodefensas. Bogotá: IEPRI-Planeta.

Ruiz, J., Illera, O. y Manrique, V. (2006). La tenue línea de la tranquilidad. Estudio comparado sobre seguridad ciudadana y policía. Bogotá: Universidad del Rosario.

Santos, J.M. (2012, 23 de mayo). Cátedra Colombia del Presidente de la República. Extraído el 24 de Junio de 2015 desde http://wsp. presidencia.gov.co/Prensa/2012/Mayo/ Paginas/20120523_09.aspx

Schultze-Kraft, M. (2005). Pacificación y poder civil en Centroamérica. Bogotá: Norma.

Schultze-Kraft, M. (2012). La cuestión militar en Colombia: la fuerza pública y los retos de la construcción de la paz. En A. Rettberg (ed.), Construcción de paz en Colombia (pp. 405433). Colombia: Universidad de los Andes.

Semana, (2013). ¿Quién le filtró a Uribe las coordenadas?. Extraído el 8 de abril de 2013 desde http://www.semana.com/nacion/ articulo/quien-le-filtro-uribe-las-coordenadas/339294-3

Semana, (2014a). ¿Alguien espió a los negociadores de La Habana?. Extraído el 3 de Febrero de 2014 desde http://www.semana.com/ nacion/articulo/alguien-espio-los-negociadores-de-la-habana/376076-3
Semana, (2014b). Chuzadas: así fue la historia. Extraído el 8 de Febrero de 2014 desde http://www.semana.com/nacion/articulo/ chuzadas-asi-fue-la-historia/376548-3

Semana, (2014c). Uribe, otra vez el primero en enterarse. Extraído el 18 de Noviembre de 2014 desde http:/www.semana.com/nacion/ articulo/alvaro-uribe-otra-vez-el-primero-en-enterarse/409442-3

Semana (2015a) El informe que sacudió el caso de la fachada Andrómeda. Extraído el 24 de Enero de 2015 desde http://www.semana. $\mathrm{com} /$ nacion/articulo/el-informe-que-sacudio-el-caso-de-la-fachada-andromeda/415642-3

Semana, (2015b). Uribe revela plan pistola de las FARC contra altos militares. Extraído el 26 de Junio de 2015 desde http://www.semana. $\mathrm{com} /$ nacion/articulo/uribe-revela-plan-pistola-de-las-farc/432679-3

Semana, (2015c). Santos a HRW: "Defenderé legitimidad de FF. MM. hasta la tumba". Extraído el 24 de Junio de 2015 desde http://www.semana.com/nacion/articulo/ santos-rechaza-el-informe-de-hrw-sobre-falsos-positivos/432402-3

Semana (2015d) El manoseo a los militares. Extraído el 25 de Abril de 2015 desde http://www. semana.com/nacion/articulo/el-manoseo-los-militares/425290-3

Velásquez, C. Coronel (r) (2011). Las fuerzas militares en la búsqueda de paz con las FARC, Working Paper, 7.Bogotá: Fundación Ideas para La Paz. 